CARTA AL EDITOR

\section{COINFECCIÓN POR SARS-COV-2 Y Mycoplasma pneumoniae: REPORTE DE 6 CASOS EN UN HOSPITAL PERUANO}

\section{SARS-COV-2 AND Mycoplasma pneumoniae COINFECTION: 6 CASE REPORT FROM A PERUVIAN HOSPITAL}

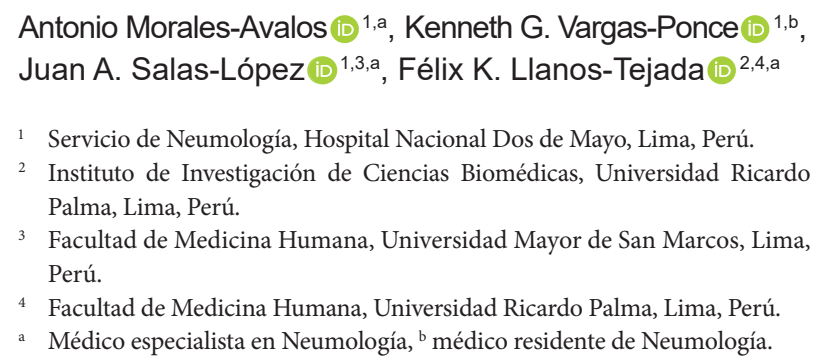
Juan A. Salas-López (iD) 1,3,a , Félix K. Llanos-Tejada (iD) 2,4,a

1 Servicio de Neumología, Hospital Nacional Dos de Mayo, Lima, Perú.

2 Instituto de Investigación de Ciencias Biomédicas, Universidad Ricardo Palma, Lima, Perú.

3 Facultad de Medicina Humana, Universidad Mayor de San Marcos, Lima, Perú.

4 Facultad de Medicina Humana, Universidad Ricardo Palma, Lima, Perú.

a Médico especialista en Neumología, ${ }^{\text {b }}$ médico residente de Neumología.

Sr. Editor: El SARS-CoV-2 es una nueva cepa de coronavirus que causa la COVID-19, ocasionando actualmente brotes epidémicos en muchos países. Al 2 de julio del 2020, los casos confirmados superaron los 10 millones en todo el mundo con más de 500000 muertes registradas. En el Perú se reportaron más de 200000 casos confirmados y más de 10000 fallecidos, siendo el segundo país de Latinoamérica con más casos, luego de Brasil. Los primeros informes de China sugirieron que la coinfección con otros patógenos respiratorios era poco frecuente ${ }^{(1)}$. Sin embargo, estudios recientes reportan tasas altas de coinfección entre el SARS-CoV-2 y otros patógenos respiratorios.

El objetivo del estudio fue describir las características demográficas, clínicas, laboratoriales y radiológicas de los pacientes con coinfección por SARS-CoV-2 y Mycoplasma pneumoniae en el Servicio de Neumología de un hospital público de Lima, para lo cual se revisaron las historias clínicas de los casos definidos como coinfección. Se estudiaron los casos que tuvieron resultados positivos de serología de IgM por inmunofluorescencia indirecta para Mycoplasma pneumoniae y de reacción en cadena de la polimerasa (PCR, por sus siglas en inglés) mediante hisopado nasofaríngeo para la COVID-19. Los datos se recopilaron entre el 1 de marzo y el 30 de abril de 2020.

\footnotetext{
Citar como: Morales-Avalos A, Vargas-Ponce KG, Salas-López JA, LlanosTejada FK. Coinfección SARS-CoV-2 y Mycoplasma pneumoniae: reporte de 6 casos en un hospital peruano. Rev Peru Med Exp Salud Publica. 2020;37(4). doi: https://doi.org/10.17843/rpmesp.2020.374.5922.
}

Correspondencia: Kenneth Grenis Vargas Ponce; Avenida Jesús María 973, Lima, Perú; grenisvp@gmail.com

Recibido: 02/06/2020 Aprobado: 08/07/2020 En línea: 05/10/2020
Se describen seis casos de coinfección por SARS-CoV-2 y Mycoplasma pneumoniae, cuyas características se muestran en la Tabla 1. El promedio de edad fue de 62 años (rango 32-87), el sobrepeso fue el factor predisponente de mayor frecuencia, con un índice de masa corporal promedio de 28,5 (rango 27-35,6). El tiempo promedio de enfermedad fue de siete días, desde el inicio de los síntomas hasta la hospitalización (rango 4-10). Los síntomas más frecuentes fueron tos no productiva, disnea, fiebre y cefalea. Sobre los exámenes de laboratorio, el 66\% presentó linfopenia $\left(<1000 \mathrm{cel} / \mathrm{mm}^{3}\right)$. El dímero D se elevó en el $50 \%$ de los pacientes, la procalcitonina sérica estuvo elevada en el 33\% de pacientes, todos presentaron insuficiencia respiratoria tipo I con $\mathrm{PaO}_{2} / \mathrm{FiO}_{2}$ promedio de $180 \mathrm{mmHg}$ (rango 93,9-315). Los hallazgos radiológicos de ingreso evidenciaron un patrón intersticial predominantemente periférico bilateral, y solo un caso presentó un patrón alveolar asociado, constatándose disociación clínica radiológica en todos los pacientes. El tratamiento médico se basó en medidas generales, los pacientes requirieron oxígeno suplementario con una fracción inspiratoria de $\mathrm{O}_{2}$ en promedio del $50 \%$.

Según las recomendaciones del Ministerio de Salud del Perú, se prescribió el tratamiento con hidroxicloroquina, azitromicina, metilprednisolona y enoxaparina ${ }^{(2)}$. En algunos pacientes se usó también ivermectina o tocilizumab. El 50\% de los pacientes evolucionó favorablemente y recibió el alta temprana. El otro 50\% evolucionó de manera desfavorable a pesar del uso de otros inmunomoduladores o antibióticos, se indicó tratamiento con doxiciclina por 10 días, luego del cual se observa mejoría clínica y radiológica; el único paciente fallecido fue un adulto mayor con diabetes e hipertensión que no recibió doxiciclina.

Seis de los 60 pacientes hospitalizados con diagnóstico de neumonía por SARS-CoV-2, presentaron infección por Mycoplasma pneumoniae, por lo que es necesario el estudio laboratorial rutinario de patógenos respiratorios comunes. Los resultados de laboratorio al ingreso son similares a los casos de infección por SARS-CoV-2 ${ }^{(1)}$, la leucocitosis estuvo presente en un $16 \%$, contrario a lo reportado por Gayan et al. ${ }^{(3)}$.

La procalcitonina es una proteína sintetizada en presencia de infecciones bacterianas, sin embargo, los valores normales de procalcitonina no descartan la infección bacteriana sobreagregada en pacientes con infección viral, como el SARS$\mathrm{CoV}-2^{(3)}$. Se ha descrito una alta resistencia a macrólidos por Mycoplasma pneumoniae ${ }^{(4)}$, lo que contrasta con el 50\% de los casos que tuvieron una evolución estacionaria hasta el cambio de antibiótico. Las tetraciclinas y quinolonas se deben usar cuando existe resistencia a macrólidos ${ }^{(5)}$; las quinolonas pueden ocasionar síndrome de QT prolongado, por lo cual se sugiere elegir tetraciclinas, como la doxiciclina, en pacientes con coinfección ante el riesgo de potenciación de drogas como la hidroxicloroquina ${ }^{(6)}$.

Dentro de las limitaciones del reporte se debe mencionar la falta de inmunodifusión sérica de IgM para Mycoplasma 
Tabla 1. Hallazgos demográficos, clínicos, laboratoriales y radiológicos en seis pacientes con coinfección de SARS-CoV-2 y Mycoplasma pneumoniae en el Hospital Nacional Dos de Mayo, Lima, Perú, 2020

\begin{tabular}{|c|c|c|c|c|c|c|}
\hline Características & Paciente 1 & Paciente 2 & Paciente 3 & Paciente 4 & Paciente 5 & Paciente 6 \\
\hline Edad (años) & 52 & 51 & 83 & 69 & 32 & 87 \\
\hline Sexo & Masculino & Masculino & Femenino & Femenino & Masculino & Masculino \\
\hline \multicolumn{7}{|l|}{ Comorbilidades } \\
\hline Diabetes & No & No & Sí & No & No & Sí \\
\hline Obesidad & Sí & No & No & No & Sí & No \\
\hline Hipertensión & No & No & Sí & No & No & No \\
\hline Asma & No & No & No & No & No & Sí \\
\hline Cáncer & No & No & No & No & No & No \\
\hline \multicolumn{7}{|l|}{ Signos y síntomas } \\
\hline Fiebre & Sí & Sí & Sí & No & Sí & No \\
\hline Tos & No & Sí & Sí & Sí & Sí & Sí \\
\hline Disnea & No & Sí & Sí & Sí & Sí & Sí \\
\hline Mialgia & No & No & Sí & No & No & Sí \\
\hline Cefalea & Sí & Sí & Sí & No & No & Sí \\
\hline Dolor abdominal & Sí & No & No & No & No & No \\
\hline Diarrea & No & No & Sí & No & No & Sí \\
\hline Expectoración & No & No & No & No & No & No \\
\hline Odinofagia & No & Sí & No & No & No & Sí \\
\hline Dolor torácico & No & No & No & Sí & No & No \\
\hline \multicolumn{7}{|l|}{ Resultados de laboratorio } \\
\hline Leucocitos $\left(\mathrm{mm}^{3}\right)$ & 11220 & 8430 & 17400 & 8770 & 10770 & 5050 \\
\hline Linfocitos $\left(\mathrm{cel} / \mathrm{mm}^{3}\right)$ & 1325 & 809 & 713 & 903 & 1720 & 621 \\
\hline Dímero D (mg/L) & 0,28 & NR & 11,7 & 8,17 & 0,42 & 3,99 \\
\hline Procalcitonina $(\mathrm{ng} / \mathrm{mL})$ & 0,11 & 0,22 & 4,9 & 0,15 & 1,42 & 0,07 \\
\hline PCR (mg/L) & 250 & 248 & 517 & 241 & 240 & 213 \\
\hline $\mathrm{PaO}_{2} / \mathrm{fiO}_{2}(\mathrm{mmHg})$ & 93,9 & 315 & 213 & 118 & 123 & 222 \\
\hline \multicolumn{7}{|l|}{ Patrones radiológicos } \\
\hline Intersticial & Sí & Sí & Sí & Sí & Sí & Sí \\
\hline Alveolar & No & No & Sí & No & No & No \\
\hline \multicolumn{7}{|l|}{ Tratamiento } \\
\hline Hidroxicloroquina & Sí & Sí & Sí & Sí & Sí & Sí \\
\hline Azitromicina & Sí & Sí & Sí & Sí & Sí & Sí \\
\hline Doxiciciclina & Sí & No & No & Sí & Sí & No \\
\hline Tocilizumab & No & No & No & No & Sí & No \\
\hline Ivermectina & No & No & Sí & No & No & No \\
\hline Metilprednisolona & Sí & Sí & Sí & Sí & Sí & Sí \\
\hline Evolución & Alta & Alta & Falleció & Alta & Alta & Alta \\
\hline
\end{tabular}

PCR: Reacción en cadena de la polimerasa, por sus siglas en inglés; NR: No realizado.

pneumoniae a los pacientes infectados con el SARS-CoV-2 que requirieron hospitalización, así como no disponer de la prueba de PCR para Mycoplasma pneumoniae, lo que nos sirve como herramienta para establecer la resistencia a macrólidos. Además, la infección por Mycoplasma pneumoniae puede ser asintomática y no severa en muchos casos.

En conclusión, la coinfección entre estos dos patógenos no es inusual, la procalcitonina no descarta la coinfección bacteriana y ante la mala evolución clínica se sugiere el uso de tetraciclinas.
Contribución de los autores: AMA, KGVP, JASL y FKLLT han participado en la concepción del artículo, recolección de datos, en la redacción y aprobación de la versión final.

Criterios éticos: Los autores declaran que los pacientes brindaron su consentimiento informado para la carta científica, además se respetó la privacidad de los pacientes. Asimismo, el Servicio de Neumología del Hospital Nacional Dos de Mayo otorgó el permiso para la publicación del reporte.

Financiamiento: Autofinanciado.

Conflictos de interés: Los autores declaran no tener conflictos de interés. 


\section{REFERENCIAS BIBLIOGRÁFICAS}

1. Chen N, Zhou M, Dong X, Qu J, Gong F, Han Y, et al. Epidemiological and clinical characteristics of 99 cases of 2019 novel coronavirus pneumonia in Wuhan, China: a descriptive study. Lancet. 2020;395(10223):507-513. doi:10.1016/S0140-6736(20)30211-7.

2. Ministerio de Salud. Modificación del Documento Técnico: Prevención Diagnóstico y Tratamiento de personas afectadas por COVID-19 en el Perú [Internet]. Lima: MINSA; 2020 [citado 29 de abril de 2020]. Disponible en: https://cdn.www.gob.pe/uploads/document/file/668361/ RM_240-2020-MINSA.PDF.

3. Gayam V, Konala VM, Naramala S, Garlapati PR, Merghani MA, et al. Presenting characteristics, comorbidities, and outcomes of patients coinfected with COVID-19 and Mycoplasma pneumoniae in the USA. J Med Virol. 2020;10.1002/jmv.26026. doi: 10.1002/jmv.26026.
4. Eshaghi A, Memari N, Tang P, Olsha R, Farrell DJ, Low DE, et al. Macrolide-resistant Mycoplasma pneumoniae in humans, Ontario, Canada, 2010-2011. Emerg Infect Dis. 2013;19(9):1525-1527. doi: 10.3201/eid1909.121466.

5. Zhou Y, Zhang Y, Sheng Y, Zhang L, Shen Z, Chen Z. More complications occur in macrolide-resistant than in macrolide-sensitive Mycoplasma pneumoniae pneumonia. Antimicrob Agents Chemother. 2014;58(2):1034-1038. doi: 10.1128/AAC.01806-13.

6. González Almarcegui I, Fernández Salvatierra L, Fuertes Schott CI, Sanz de Galdeano Delgado S, Val Jordan E, Mora Rangil P. Síndrome de QT largo y torsades de pointes tras la administración de levofloxacino. Rev Cuban Cardiol [Internet]. 2014 [citado el 5 de julio de 2020] Disponible en: http://www.revcardiologia.sld.cu/index.php/ revcardiologia/article/view/343. 